\title{
Kosteuden vaikutus energiapuun polton kannattavuuteen
}

\author{
Tuomas Hakonen \\ Seinäjoen ammattikorkeakoulu, Maa- ja metsätalouden yksikkö \\ Tuomarniementie 55, 63700 Ähtäri \\ tuomas.hakonen@seamk.fi
}

\section{Tiivistelmä}

Maatilat ovat merkittäviä hakkeen käyttäjiä, joten energiapuun polton taloudellisuus on niille erityisen tärkeää. Kosteus on yksi merkittävimmistä hakkeen käytön kannattavuuteen vaikuttavista tekijöistä. Kosteus vaikuttaa hakkeesta saatavaan energiamäärään sekä tehollisen lämpöarvon että polton hyötysuhteen kautta. Tässä tutkimuksessa selvitettiin laskennallisesti eri kosteusprosentteja omaavien tasakokoisten hake-erien energiasisältöjä. Puun lämpöarvo eri kosteuksissa on selvitetty aiemmalla tutkimuksella varsin kattavasti ja myös polttolaitosten energiasta saama keskimääräinen hinta on tiedossa. Näitä tietoja yhdistämällä tehtiin laskelmia kosteuden vaikutuksesta hakkeen polton kannattavuuteen. Selvitys tehtiin kirjallisuustutkimuksena.

Hakekuorman $\left(120 \mathrm{i}-\mathrm{m}^{3}\right)$ sisältämän energian myyntitulot tuoreelle hakkeelle (kosteus $55 \%$ ) ovat $2747 €$. Vastaava lukuarvo kosteusprosentilla 40 on $2971 €$. Lukuarvot perustuvat energiankulutuksen mukaisiin maksuihin. Esitettyjä lukuarvoja vertaamalla havaitaan, että jo yhdessä hakekuormassa kuivauksen hyöty on vähintään $224 €$. Hyvissä olosuhteissa energiapuuta kuivaamalla päästään kuitenkin varsin helposti alle $40 \%$ kosteuksiin. Esimerkiksi $30 \%$ tasolla kuivauksella saatava hyöty olisi $321 €$. Jos vastaava vertailu tehdään huomioiden hakeauton kantavuus, mikä estää kuljetustilavuuden täysimääräisen hyödyntämisen korkeilla kosteusprosenteilla, ovat hyödyt jo $589 €$ (kosteus \% 40) ja $686 €$ (kosteus \% 30). Voidaan siis sanoa, että jo yhdessä hakekuormassa kuivauksella saatava taloudellinen hyöty on merkittävä. Korkotuottoja tarkastelemalla päädytään samaan lopputulokseen. Tavanomaisella vuoden kuivatusajalla päästään helposti yli $10 \%$ lisätuottoon, mikä on erinomainen prosentti, kun verrataan sitä esimerkiksi pankkien pääomalle maksamaan korkoon. Tässä tutkimuksessa korkotuotto laskettiin myyntituloista.

Energian myyntihinta tulee todennäköisesti tulevaisuudessa nousemaan, jolloin kuivattamisesta saatava hyöty kasvaa. Kun vielä ajatellaan metsäenergian suuria tulevaisuuden käyttötavoitteita, joihin pääseminen on muutoinkin haasteellista, ei ole järkevää heittää energiaa hukkaan polttamalla kosteaa haketta. Kuivauksella saatava tuotto on ehdottomasti järkevää hyödyntää.

Asiasanat: bioenergia, kosteus, kannattavuus 


\section{Johdanto}

Energiapuun kosteus heikentää tunnetusti polton kannattavuutta. Lisäksi energiapuun kosteudella on myös muita negatiivisia vaikutuksia käytettävyyteen. Tämän tutkimuksen alussa näitä vaikutuksia käydään lyhyesti läpi, minkä jälkeen keskitytään tarkastelemaan kosteuden vaikutusta (metsä)hakkeen polton kannattavuuteen.

Kosteus vaikuttaa hakkeesta saatavaan energiamäärään sekä tehollisen lämpöarvon että polton hyötysuhteen kautta. Tehollinen lämpöarvo laskee, koska kosteuden haihduttaminen kuluttaa poltettaessa energiaa. Polton hyötysuhteen aleneminen taas johtuu kosteuden aiheuttamasta epätäydellisesti palamisesta ja toisaalta matalammasta palamislämpötilasta (Hakkila 2004). Korkea kosteusprosentti lisää suuremmasta painosta johtuen kuljetuskustannuksia sekä myös polttolaitosten hiilimonoksidi-, hiilivety- ja hiukkaspäästöjä. Kosteus huonontaa lisäksi selvästi polttoaineen varastoitavuutta. Kemiallisten ja biologisten prosessien seurauksena puumateriaalissa syntyy sekä kuiva-ainetappioita että terveydelle haitallisia mikrobikasvustoja. Prosessit hidastuvat vasta alle $25 \%$ kosteudessa, johon hakkeen tuotannossa päästään harvoin (Hakkila 2004). Tämä käytännössä estää metsähakkeen pitkäaikaisen ulkovarastoinnin. Liian kostea hake myös jäätyy talvella, mikä aiheuttaa tukoksia polttolaitosten syöttölinjoille ja kuljettimille sekä vaikeuttaa hakeauton kuorman purkamista.

Tällä tutkimuksella selvitetään laskennallisesti eri kosteusprosentteja omaavien tasakokoisten hake-erien energiasisältöä ja tähän perustuen hake-erien polton kannattavuutta. Puun lämpöarvo eri kosteuksissa on aiemmalla tutkimuksella varsin kattavasti selvitetty ja näitä tuloksia hyödynnetään hake-erän energiasisältöä määritettäessä. Myös polttolaitosten energiasta saamasta keskimääräisestä hinnasta on tehty selvityksiä. Tietoja yhdistämällä tehdään laskelmia kosteuden vaikutuksesta hakkeen polton kannattavuuteen. Tutkimus tehtiin kirjallisuustutkimuksena ja laskelmia laatien.

\section{Kosteuden vaikutus metsähakkeen polton kannattavuuteen}

\section{Metsähakkeen lämpöarvo}

Metsähakkeen lämpöarvo on tiedettävä, jotta voidaan laskea kosteuden vaikutusta polton kannattavuuteen. Tässä tutkimuksessa ei tehdä mittauksia metsähakkeen lämpöarvoista, vaan hyödynnetään aiempien tutkimusten tuloksia. Hakelajien lämpöarvot (kuiva-aineen tehollinen lämpöarvo, $\mathrm{MJ} / \mathrm{kg}$ ) ovat Alakankaan (2000) useista lähteistä (Hakkila ym. 1978, Pellikka \& Saviharju 1983, Laine \& Sahrman 1985, Tahvanainen 1995, Taipale 1996, Wilén ym. 1999) keräämien tietojen perusteella varsin lähellä toisiaan. Laskelmat voidaan näin ollen tehdä yhden lämpöarvon pohjalta. Tässä tutkimuksessa käytetään männyn kokopuuhakkeen lämpöarvoa $(19,6 \mathrm{MJ} / \mathrm{kg})$.

Koska tavoitteena on selvittää kosteuden vaikutusta lämpöarvoon, lasketaan tulokset saapumistilassa olevan polttoaineen teholliselle lämpöarvolle. Tämä lämpöarvo huomioi polttoaineessa olevan veden, kun kuiva-aineen tehollinen lämpöarvo lasketaan täysin vedettömälle polttoaineelle. Kuivaaineen tehollinen lämpöarvo $(19,6 \mathrm{MJ} / \mathrm{kg})$ muutetaan saapumistilassa olevan polttoaineen teholliseksi lämpöarvoksi käyttämällä yhtälöä (CEN/TS 14918:2005):

$\mathrm{Q}_{\text {net, ar }}=\mathrm{Q}_{\text {net, } \mathrm{d}} \times\left(\left(100-\mathrm{M}_{\mathrm{ar}}\right) / 100\right)-0,02443 \times \mathrm{M}_{\mathrm{ar}}$

$\mathrm{Q}_{\text {net, ar }}=$ tehollinen lämpöarvo saapumistilassa $(\mathrm{MJ} / \mathrm{kg})$

$\mathrm{Q}_{\text {net, } \mathrm{d}}=$ tehollinen lämpöarvo kuiva-aineessa $(\mathrm{MJ} / \mathrm{kg})$

$\mathrm{M}_{\mathrm{ar}}=$ kosteus saapumistilassa [p- \%]

$0,02443(\mathrm{MJ} / \mathrm{kg})$ on veden höyrystymiseen kuluva lämpömäärä $\left(+25^{\circ} \mathrm{C}\right)$

Yhtälöä hyödyntämällä lasketaan lämpöarvot eri kosteuksissa (Taulukko 1). Yhtälö antaa tulokset $\mathrm{MJ} / \mathrm{kg}$, jonka jälkeen ne muunnetaan yleisimmin käytettyyn $\mathrm{kWh} / \mathrm{kg}$ muotoon. 
Taulukko 1. Hakkeen tehollinen lämpöarvo saapumistilassa eri kosteusprosenteilla ( $1 \mathrm{kWh} / \mathrm{kg}=3,6 \mathrm{MJ} / \mathrm{kg})$. Laskennassa kuiva-aineen tehollisena lämpöarvona on käytetty arvoa 19,6 MJ/kg.

\begin{tabular}{|c|c|c|}
\hline $\begin{array}{l}\text { Polttoaine-erän kokonais- } \\
\text { kosteus saapumistilassa \% }\end{array}$ & $\begin{array}{l}\text { Tehollinen lämpöarvo } \\
\text { saapumistilassa MJ/kg }\end{array}$ & $\begin{array}{l}\text { Tehollinen lämpöarvo } \\
\text { saapumistilassa } \mathbf{k W h} / \mathbf{k g}\end{array}$ \\
\hline 55 & 7,48 & 2,08 \\
\hline 50 & 8,58 & 2,38 \\
\hline 45 & 9,68 & 2,69 \\
\hline 40 & 10,78 & 3,00 \\
\hline 35 & 11,89 & 3,30 \\
\hline 30 & 12,99 & 3,61 \\
\hline 25 & 14,09 & 3,91 \\
\hline 20 & 15,19 & 4,22 \\
\hline 15 & 16,29 & 4,53 \\
\hline 10 & 17,40 & 4,83 \\
\hline 5 & 18,50 & 5,14 \\
\hline 0 & 19,60 & 5,44 \\
\hline
\end{tabular}

\section{Hyötysuhde}

Polton hyötysuhteella kuvataan talteen saatavan energian määrää suhteessa polttoaineen sisältämän energian kokonaismäärään eli energiasisältöön (Wahlroos 1980). Hyötysuhde on, energiasisällön ohella, toinen polttoaineesta saatavaan energiamäärään vaikuttava tekijä. Hyötysuhteeseen vaikuttavat monet tekijät. Flyktman ja Helynen (2004) ovat esittäneet kolmeksi tärkeimmäksi hyötysuhteeseen vaikuttavaksi tekijäksi polttoaineen kosteutta, savukaasujen loppulämpötilaa ja ilmakerrointa. Ilmakertoimella tarkoitetaan palamiseen tarvittavan todellisen ja teoreettisen ilmamäärän suhdetta.

Savon voimalle tehdyssä selvityksessä (Savon Voima Oy:n... 2004) kosteus heikensi hyötysuhdetta noin 1,5 prosenttiyksikköä kosteuden muuttuessa $40 \%$ :sta $55 \%$ :iin kattilakokoluokassa 3 - 10 MW. Samansuuntainen tulos on saatu myös Flyktmanin ja Helysen (2004) tekemässä tutkimuksessa. Tutkimuskohteena oli 120 MW:n leijupetikattila. Kummassakaan tutkimuksessa ei ole tarkasteltu hyötysuhteen muuttumista, kun kosteus laskee alle $40 \%$ :iin. Kosteuden vaikutus hyötysuhteeseen kuitenkin hyvin todennäköisesti suhteellisesti vähenee, kun kosteusprosentit pienenevät (Flyktman M sähköpostitiedonanto 5.5.2011).

Yllä mainituissa tutkimuksissa kosteuden vaikutus hyötysuhteeseen on korkeintaan muutama prosenttiyksikkö, kun kosteusprosentti on 20 - 55. Tutkimusten kuvaajat kuitenkin päättyvät kosteusprosenttiin 40, joten siitä alaspäin hyötysuhteen muutos perustuu arvioon. Toisaalta kattilan koolla ja tyypillä on merkittävä vaikutus siihen, kuinka paljon kosteus vaikuttaa hyötysuhdekuvaajaan (Liukkonen H suullinen tiedonanto 21.4.2011, Flyktman M sähköpostitiedonanto 5.5.2011). Hyötysuhteeseen vaikuttavat tekijät myös korreloivat voimakkaasti keskenään (Flyktman \& Helynen 2004). Yllä mainituilla perusteilla kosteuden vaikutusta hyötysuhteeseen ja edelleen tämän vaikutusta polton kannattavuuteen ei oteta tämän tutkimuksen tulosten laskennassa huomioon.

\section{Kuormakoko}

Jotta tutkimuksen tavoitteena olevan energiasisällön laskeminen hakekuormalle olisi mahdollista, on tiedettävä hakekuorman massa. Hakekuorman massa lasketaan kuormatilavuuteen perustuen. Halosen ja Vesisenahon (2002) sekä Kuiton (2005) selvitysten mukaan kiinteäkuormatilaisen hakeauton kuormatilavuus on noin 120 i- $\mathrm{m}^{3}$ eli 48 kiintokuutiometriä $\left(\mathrm{m}^{3}\right)$. Nyt hake-erän massa saadaan selville käyttämällä puun kuiva-tuoretiheyttä. Tutkimuksessa käytetään arvoa $400 \mathrm{~kg} / \mathrm{m}^{3}$, mikä vastaa männyn ja 
kuusen kuiva-tuoretiheyttä. Kiintokuutioiden ja kuiva-tuoretiheyden avulla lasketaan hake-erän massa, joka on näin ollen $48 \mathrm{~m}^{3}$ x $400 \mathrm{~kg} / \mathrm{m}^{3}=19200 \mathrm{~kg}$. Koska kuiva-tuoretiheys määritetään $0 \%$ kosteudessa olevalle puuaineelle, on määritetyn massan $(19200 \mathrm{~kg})$ päälle lisättävä vielä veden massa.

On mahdollista, että korkeilla kosteusprosenteilla kuorman massa nousee niin korkealle, että auton sallittu kokonaiskantavuus ylitetään. Tällöin kuormakoon rajoittavaksi tekijäksi tulee massa ja koko kuormatilavuutta ei voida enää hyödyntää. Kiinteäkuormatilaisen hakeauton kantavuus on noin $37000 \mathrm{~kg}$ (Halonen \& Vesisenaho 2002, Kuitto 2005). Kuorman ja hakeauton sallittu yhteismassa on $60000 \mathrm{~kg}$. Tämä on otettava tulosten laskennassa huomioon.

\section{Tulokset}

\section{Energiasisältö}

Aiemmin määritettiin metsähakkeelle teholliset lämpöarvot saapumistilassa eri kosteuksilla (Taulukko 1). Nämä arvot on esitetty muodossa $\mathrm{kWh} / \mathrm{kg}$. Kertomalla nämä lämpöarvot hake-erän massoilla saadaan energiasisällöt eri kosteusprosenteilla. Lisäksi näin saadut arvot muunnetaan kWh:sta MWh:ksi. Nämä tulokset on esitetty taulukossa 2 .

Taulukko 2. Hake-erän (120 i-m $\left.{ }^{3}\right)$ massa ja energiasisältö eri kosteusprosenteilla.

\begin{tabular}{|c|c|c|c|c|}
\hline Kosteus \% & $\begin{array}{l}\text { Hake-erän } \\
\text { massa kg }\end{array}$ & $\begin{array}{l}\text { Hake-erän } \\
\text { energiasisältö } \\
\text { MWh }\end{array}$ & $\begin{array}{l}\text { Hake-erän massa } \\
\text { (auton kantavuus } \\
\text { huomioitu) kg }\end{array}$ & $\begin{array}{l}\text { Hake-erän energiasisältö } \\
\text { (auton kantavuus huomi- } \\
\text { oitu) MWh }\end{array}$ \\
\hline 55 & 42667 & 88,6 & $\mathbf{3 7 0 0 0}$ & $\mathbf{7 6 , 9}$ \\
\hline 50 & 38400 & 91,5 & $\mathbf{3 7 0 0 0}$ & $\mathbf{8 8 , 2}$ \\
\hline 45 & 34909 & 93,9 & 34909 & 93,9 \\
\hline 40 & 32000 & 95,9 & 32000 & 95,9 \\
\hline 35 & 29538 & 97,5 & 29538 & 97,5 \\
\hline 30 & 27429 & 99,0 & 27429 & 100,2 \\
\hline 25 & 25600 & 100,2 & 25600 & 101,3 \\
\hline 20 & 24000 & 101,3 & 24000 & 102,2 \\
\hline 15 & 22588 & 102,2 & 22588 & 103,1 \\
\hline 10 & 21333 & 103,1 & 21333 & 104,5 \\
\hline 5 & 20211 & 103,8 & 20211 & \\
\hline 0 & 19200 & 104,5 & 19200 & \\
\hline
\end{tabular}

\section{Myyntitulot}

Tieto hake-erän energiasisällöstä eri kosteusprosenteilla mahdollistaa myyntitulojen vertailun. EteläPohjanmaan metsäkeskusalueella toimivien lämpöyrittäjien kokonaistulot vuosina 2006 - 2007 olivat keskimäärin 56,2€/MWh (alv:ton). Tästä $31 € / M W h$ tuli energiankulutukseen perustuvista maksuista ja 13,1 $€ / M W h$ kiinteästä maksusta. Muusta liiketoiminnasta lämpöyrittäjät saivat tuloja keskimäärin 12,2 €/MWh. (Sauvula-Seppälä 2010.)

Energiakulutuksen perustuvaa hintaa (31€/MWh) käytetään myyntitulojen vertailulaskentaan. Tämän lukuarvon käyttäminen on perusteltua, koska vain se on suoraan riippuvainen tuotetusta energiamäärästä. Energiakulutukseen perustuvalla hinnalla $(31 € / \mathrm{MWh})$ kerrotaan hake-erälle eri kosteusprosenteilla saadut energiasisällöt. Näin saatuja lukuarvoja vertaamalla nähdään kuivattamisella saatava euromääräinen hyöty (kuva 1). 


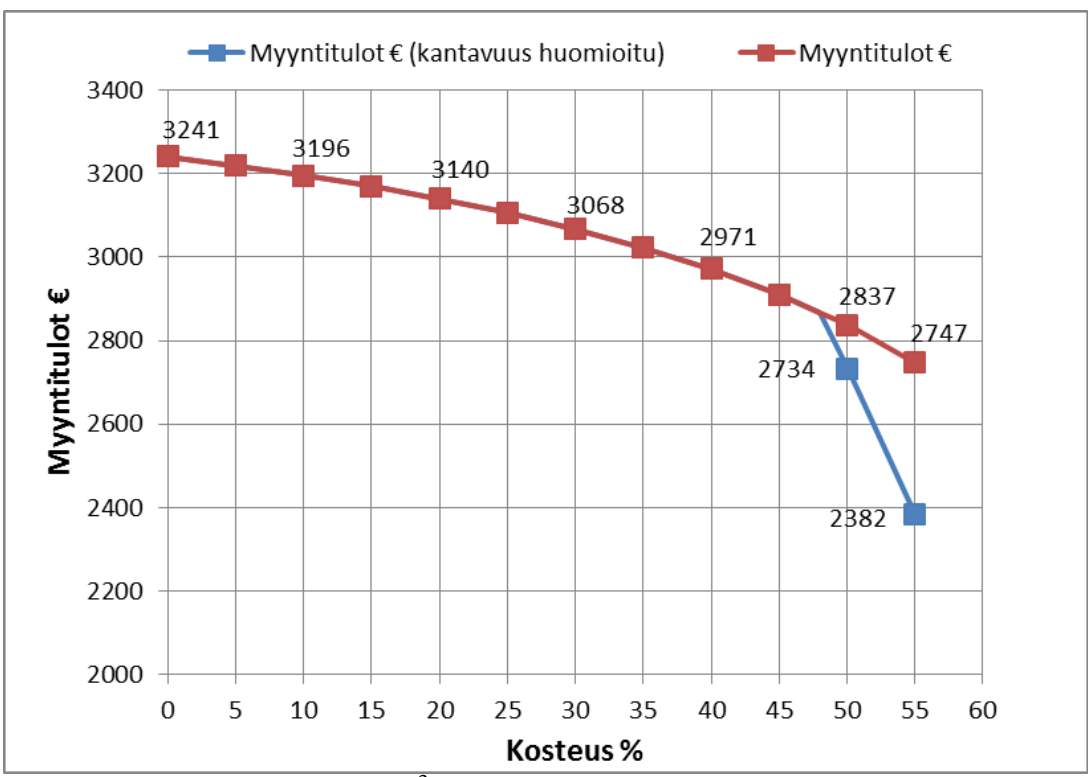

Kuva 1. Hake-erästä $\left(120 \mathrm{i}-\mathrm{m}^{3}\right)$ saatavat energian myyntitulot (31 €/MWh) eri kosteusprosenteilla. Sininen kuvaaja ottaa huomioon auton kantavuuden $(37000 \mathrm{~kg})$ eli kuormatila jää vajaaksi. Punaisen kuvaajan tapauksessa kuormatila täytetään kokonaan. Huom! $31 € / \mathrm{MWh}$ on energiankulutukseen perustuva hinta, jossa ei ole mukana kiinteitä maksuja.

\section{Tulosten tarkastelu ja johtopäätökset}

Eri puulajeista tehdyt hakkeet ovat lämpöarvoltaan $(\mathrm{MWh} / \mathrm{kg})$ varsin lähellä toisiaan, joten yhden keskimääräisen lämpöarvon valitseminen tulosten laskennan pohjaksi ei aiheuta tutkimukseen suurta virhettä. Polton hyötysuhde on sen sijaan huomattavasti ongelmallisempi tekijä. Vaikka kosteuden vaikutus polton hyötysuhteeseen on keskimäärin varsin pieni, voi sen vaikutus yksittäisille polttolaitoksilla olla huomattava.

Tutkimuksen tuloksissa on esitetty laskelmat kosteusprosenttiin nolla asti. Lähellä nollaa olevat kosteusprosentit ovat lähinnä teoreettisia. Käytännössä ulkokuivatuksessa ei energiapuun kosteus laske alle 15 prosentin ja yleisesti kosteusprosentit ovat vuoden kuivatuksen jälkeen välillä 20 - 40 (Karttunen ym. 2010, Laurila \& Lauhanen 2010).

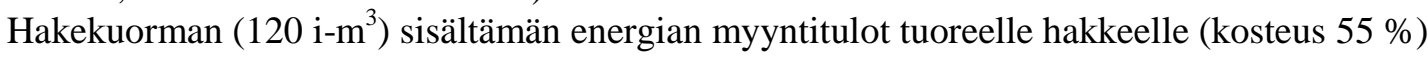
ovat $2747 €$ (kuva 1). Vastaava lukuarvo kosteusprosentilla 40 on $2971 €$. Eli jo yhdessä hakekuormassa kuivauksen hyöty on vähintään $224 €$. Kuivaamalla päästään kuitenkin varsin helposti $40 \%$ alempiinkin kosteuksiin. Esimerkiksi $30 \%$ tasolla kuivauksella saatava hyöty olisi $321 €$. Jos vastaava vertailu tehdään auton kantavuus huomioiden, niin lukemat ovat jo $589 €$ (kosteus $40 \%$ ) ja $686 €$ (kosteus $30 \%$ ). Kuivauksen vaikutus polton kannattavuuteen on huomattava.

Vaikka energiapuun kuivaaminen lisääkin energiasisältöä ja energian myyntituloja, aiheuttaa pitkä varastointi-/kuivausaika aina jonkin verran kuiva-aine tappioita. Kuiva-aine tappioita syntyy sekä puun osien irtoamisen että puuaineessa tapahtuvien hajoamisprosessien takia. Anerudin ja Jirjisin (2011) tekemässä tutkimuksessa 13 kuukautta varastoiduilla kuusen kannoilla kuiva-aine tappioiden määrä oli 4,0 - 8,3 \% kuiva-aineen massasta. Petterssonin ja Nordfjellin (2007) tekemässä tutkimuksessa hakkuutähdepaalien kuiva-ainetappiot vuoden varastointiajalla olivat 14,4-17,4\%.

Energiapuukaupan hinnoitteluperusteena on useimmiten tilavuus, mutta energiasisältöön perustuva hinnoittelu on yleistymässä. Energiasisältöön perustuvan hinnoittelun yleistyessä puun myyjän mahdollisuus vaikuttaa omaan tulotasoonsa paranee ja kiinnostus energiapuun kuivaamiseen kasvaa.

Energian myyntihinta tulee todennäköisesti tulevaisuudessa nousemaan, jolloin kuivattamisen merkitys korostuu. Toisaalta on oletettavaa, että energiapuun hinta seuraa ainakin jossain määrin nousevaa energian hintaa, jolloin taloudellinen hyöty pysyy suunnilleen nykyisellä tasolla. Kuivauksella saatava tuotto on ehdottomasti järkevää hyödyntää. 


\section{Kirjallisuusluettelo}

Alakangas, E. 2000. Suomessa käytettävien polttoaineiden ominaisuuksia. VTT tiedotteita 2045. Otamedia Oy, Espoo. $172 \mathrm{~s}$.

Anerud, E. \& Jirjis, R. 2011. Fuel quality of Norway spruce stumps - influence of harvesting technique and storage method. Scandinavian Journal of Forest Research 26/2011: 257 - 266.

CEN/TS 14918:2005 Solid Biofuels - Method for determination of calorific value. $62 \mathrm{~s}$

Flyktman, M. \& Helynen, S. 2004. Hyötysuhteiden määrittäminen päästökaupan alkujakoa varten. Tutkimusselostus. VTT Prosessit, Jyväskylä. $25 \mathrm{~s}$.

Hakkila, P. 2004. Puuenergian teknologiaohjelma 1999 - 2003. Metsähakkeen tuotantoteknologia. Loppuraportti. $135 \mathrm{~s}$.

Hakkila, P., Kalaja, H., Salakari, M. \& Valonen, P. 1978. Whole-tree harvesting in the early thinning of pine. Folia Forestalia 333: $1-58$.

Halonen, P. \& Vesisenaho, A. 2002. Hakeautoseuranta. Hankeraportti. VTT Prosessit, Jyväskylä. 25 s.

Karttunen, K., Föhr, J. \& Ranta, T. 2010. Energiapuuta Etelä-Savosta. Lappeenrannan teknillinen yliopisto. Teknillinen tiedekunta. LUT Energia. Tutkimusraportti 7. $150 \mathrm{~s}$.

Kuitto, P-J. 2005. Hakeautokalustosta. Julkaisussa: Kuitto, P-J. (toim.). Metsästä polttoaineeksi - Polttohakkeen tuotannon puoli vuosisataa. FINBIO - Suomen Bioenergiayhdistys ry. s. 305 - 306.

Laine, R. \& Sahrman, K. 1985. Puupolttoaineiden ominaisuudet ja hinnoitteluperusteet. Tiedotteita 513. Valtion teknillinen tutkimuskeskus, Espoo. $68 \mathrm{~s}$.

Laurila, J. \& Lauhanen, R. 2010. Moisture Content of Norway Spruce Stump Wood at Clear Cutting Areas and Roadside Storage Sites. Silva Fennica. Vol 44(3), 2010: 427 - 434.

Pellikka, J. \& Saviharju, K. 1983. Kuoren ja puujätteen poltto. Teoksessa: Puumassan valmistus II. Osa 2. s. $1519-1982$.

Pettersson, M. \& Nordfjell, T. 2007. Fuel quality changes during seasonal storage of compacted logging residues and young trees. Biomass \& bioenergy 31: $782-792$.

Sauvula-Seppälä, T. 2010. Lämpöyrittäjyyden kannattavuus lämmönostajan ja -myyjän sekä metsänomistajan näkökulmasta. Maataloustieteen päivät 2010. 7 s.

Savon Voima Oy:n Bioenergiaohjelma. 2001. Savon Voima Oy, Kuopio. 191 s.

Tahvanainen, L. 1995. Pajun viljelyn perusteet. Silva Carelica 30. Joensuun yliopisto, Metsätieteellinen tiedekunta. $126 \mathrm{~s}$.

Taipale, R. 1996. Kiinteiden polttoaineiden ominaisuudet. Jyväskylän yliopisto. Pro gradu -tutkielma. 138 s.

Wahlroos, L. 1980. Kotimaiset polttoaineet ja keskuslämmityskattilat. Energiakirjat Ky, Pori. 372 s.

Wilén, C., Moilanen, A., Rautalin, A., Torrent, J., Conde, E., Lödel, R., Carson, D., Timmers, P. \&

Brehm, K. 1999. Safe handling of renewable fuels and fuel mixtures. VTT Publications 394. Technical Research Centre of Finland, Espoo. 117 s. 